\title{
Oxidative rearrangement of acetylporphyrins
}

\section{Manas Chakrabarty}

Department of Chemistry, Bose Institute, 93/1, A. P. C. Road, Kolkata-700 009, India

E-mail : manas@boseinst.ac.in

Manuscript received 31 August 2001

Oxidative rearrangement of 2-/4-monoacetyl- and 2,4-diacetyldeuteroporphyrin IX dimethyl esters by methanolic thallic nitrate trihydrate in presence of conc. nitric acid furnished the corresponding mono- and dimethoxycarbonylmethylporphyrins, respectively.

The mysteries of porphyrin chemistry continue to trigger worldwide research in the two thrust areas of unravelling the fundamentals of photosynthesis and unveiling the role of porphyrins in catalysing a diverse array of bio-energetic reactions. Research in these fields is now providing us with a deeper insight into the role of porphyrins and their future applications ${ }^{1}$.

In haem biosynthesis, it was established years ago that 'the decarboxylation of uroporphyrinogen III (1) to coporphyrinogen III (2) is a stepwise process taking place by a preferred pathway (both in normal and abnormal metabolism); the acetic acid groups are decarboxylated in a sequential clockwise fashion starting with that on the $d$ ring and followed by those on the $\mathrm{a}, \mathrm{b}$ and $\mathrm{c}$ rings' ${ }^{2}$ (Scheme 1 ). The pentacarboxylic porphyrinogen 3 is thus an intermediate in haem biosynthesis.

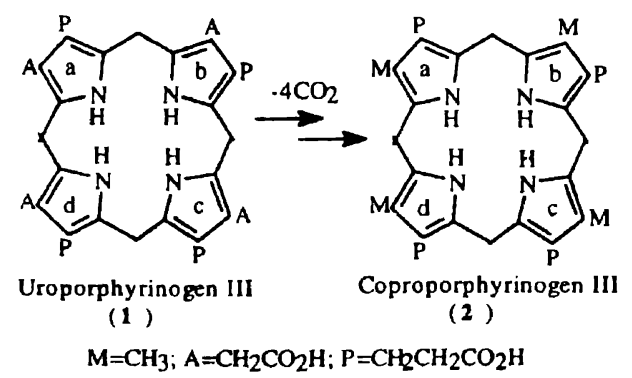

Scheme 1

In connection with an enzymatic study on uroporphyrinogen decarboxylase, the enzyme responsible for the conversion of 1 to 2 , the development of a new synthesis of the pentamethyl ester 4 of the naturally occurring porphyrin corresponding to the porphyrinogen 3 with a radiolabel $\left({ }^{14} \mathrm{C}\right)$ at the carboxylic carbon of the acetic acid side-chain became necessary.

It was planned to achieve the same by the oxidative rearrangement of the corresponding acetylporphyrin 5 by thal-
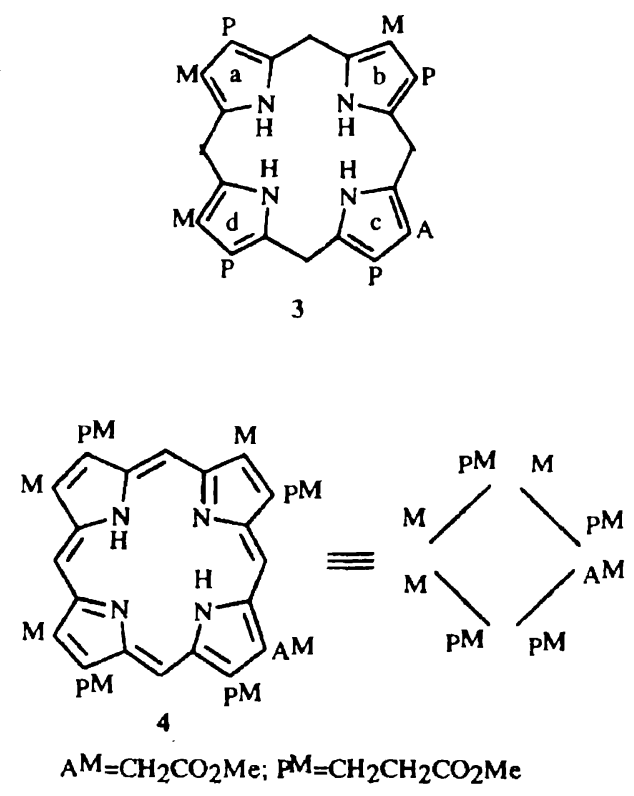

lium (III) nitrate in methanol in presence of conc. nitric acid (Scheme 2) - a reagent which is known to transform an acetyl group to a methoxycarbonylmethyl moiety ${ }^{3}$.

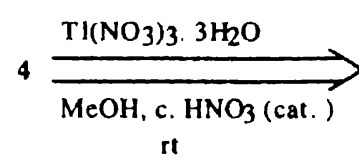

Scheme 2

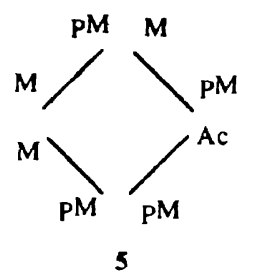

5
This rearrangement is known to involve sequential enolisation of the ketone, oxythallation of the carbon-carbon double bond thus formed and 1,2-aryl migration with concomitant reduction of thallium(III) to thallium(1) ${ }^{3}$ (Scheme 3).

However, to the best of our knowledge, this reaction has 
not yet been tried on the porphyrin ring, presumably since the reaction was reported to fail in the case of compounds
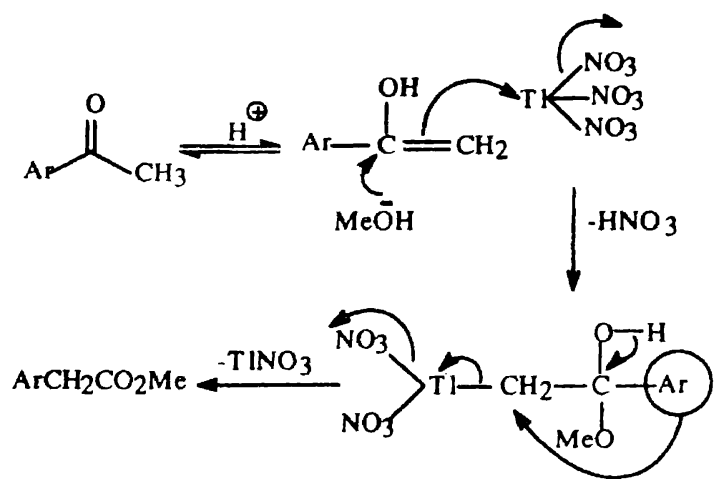

Scheme 3

having NH group because of the preferential complexation of thallium with it. While we were envisaging to try this reaction on the acetylporphyrin 5 , three reports ${ }^{4-6}$, published in the same year by one particular group, drew our attention. In these reports, the preparation, spectroscopic identification and reactions of the thallium(III), iron(III), copper(II), nickel, zinc and magnesium chelates of porphyrins were studied. These workers demonstrated that porphyrins react with stoichiometric amounts of thallium trifluoroacetate, followed by an aqueous work-up, or directly with thallic nitrate trihydrate (TTN) to furnish the corresponding aquo-thallium complexes, e.g. the chelate 7 from coproporphyrin I tetramethyl ester (6).(Scheme 4).

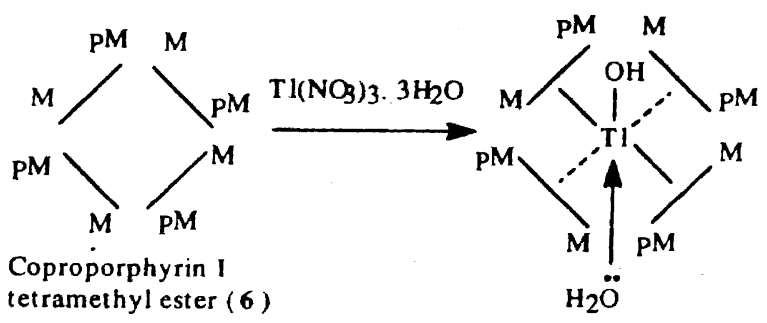

Scheme 4

In view of this information, we were inclined to believe that the use of two equivalents of TTN to the acetylporphyrin $\mathbf{5}$, or of one equivalent of TTN to a preformed aquo-thallium complex of 5 should bring about the desired transformation to the corresponding methoxycarbonylmethylporphyrin. It was, therefore, decided to study the action of TTN on two model acetylporphyrins, viz. monoacetyl- and diacetyldeuteroporphyrin IX dimethyl esters. The results of our experiments have been presented in this communication.

Accordingly, deuteroporphyrin IX dimethyl ester $(\mathbf{8})^{7}$, henceforth abbreviated as DP-IX-DME, was prepared from the commercially available hemin by Schumm reaction ${ }^{8-10}$, i.e. by protiodevinylation by heating with resorcinol, followed by demetallation and then reesterification of the resulting DP-IX with methanolic hydrochloric acid. Acetylation of the copper chelate of $\mathbf{8}$ by acetic anhydride in presence of stannic chloride, followed by demetallation (by treatment with a mixture of conc. sulfuric acid and trifluoroacetic acid) and reesterification (with methanolic sulfuric acid) resulted in the formation of a mixture of the 2-/4-monoacetyland 2,4-diacetyl-DP-IX-DMEs ( 9 and 10, respectively) (Scheme 5) which were separated by column chromatography over alumina.

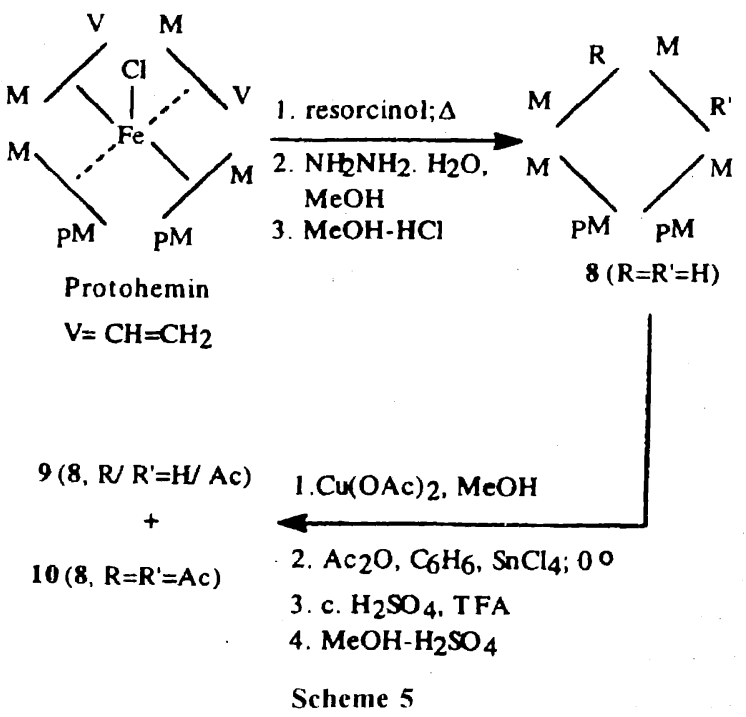

The mixture of the 2- and 4-monoacetylporphyrins (9) was then treated with two equivalents of methanolic TTN in presence of catalytic amount of conc. nitric acid. After the completion of the reaction, a usual work-up involving demetallation $\left(\mathrm{SO}_{2}(\mathrm{~g}) / \mathrm{c}\right.$. $\left.\mathrm{HCl}\right)$, reesterification $(\mathrm{MeOH}-$ $\mathrm{H}_{2} \mathrm{SO}_{4}$ ) and purification by $\mathrm{CC}$ and then prep. TLC furnished the major product in pure state. It was identified as the desired rearrangement product $\mathbf{1 1}$ by elemental analysis, UV, mass and ${ }^{1} \mathrm{H}$ NMR spectral data (vide Experimental) (Scheme 6).

The poor yield of the desired product 11 notwithstanding, the reaction was next applied to the diacetyl derivative 10 , this time using three equivalents of TTN, as may be expected. The reaction was carried out at $35-40^{\circ}$ for nearly $5 \mathrm{~h}$, and a similar follow-up as before resulted in the isolation of the major product in a comparable yield. It was identified as the expected tetramethyl ester 12 by elemental and spectroscopic analyses (Scheme 7).

The structure of 12 was further verified by its synthesis 
Chakrabarty : Oxidative rearrangement of acetylporphyrins

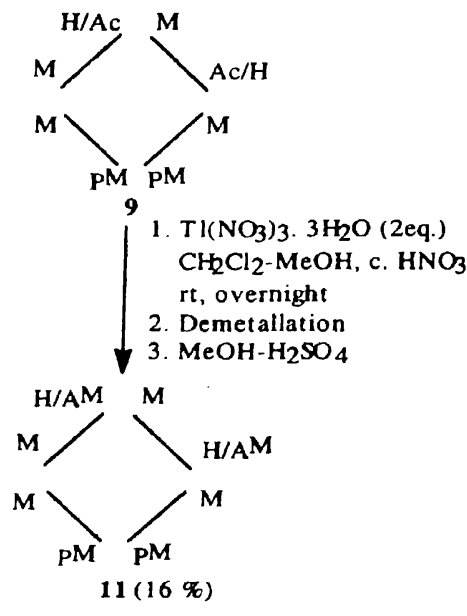

Scheme 6

from two appropriate dipyrrylmethanes by the modified ${ }^{11}$ MacDonald route ${ }^{12,13}$. Thus, the 5,5'-diformylpyrromethane $14^{14}$, prepared from the pyrrole 13 through a three-step procedure, was subjected to para-toluene sulfonic acid-catalysed

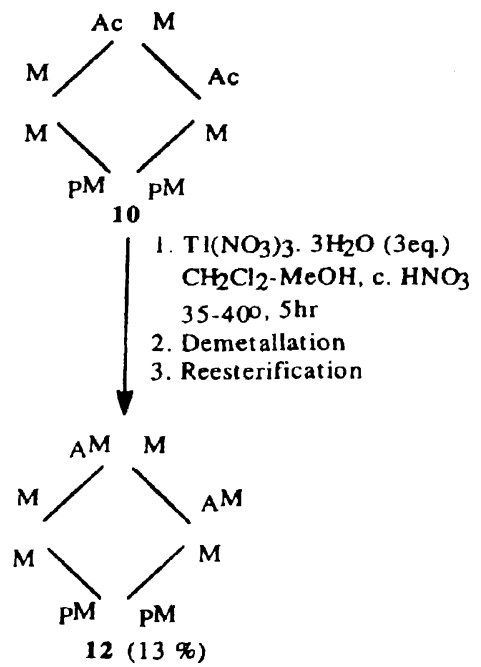

Scheme 7

condensation with the pyrromethane-5,5'-dicarboxylic acid $15^{15}$ in the conventional way. A usual work-up, followed by purification by $\mathrm{CC}$, furnished a porphyrin in $20 \%$ yield (Scheme 8). Its identity with the rearrangement product 12 was confirmed by usual comparisons.

The results thus demonstrated the applicability of the acid-catalysed oxidative rearrangement by methanolic thallic nitrate in the field of porphyrins as well. However, the reaction, as applied to porphyrins, suffers from a serious drawback that a number of byproducts are always formed,

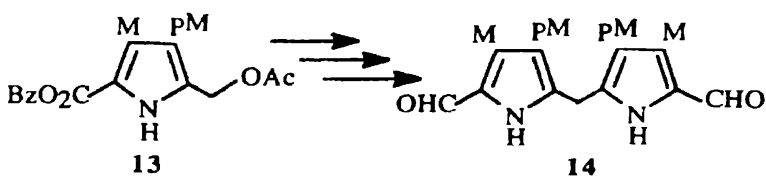<smiles>[M]c1cc(Cc2[nH]c(C(=O)O)c([M])c2[M])[nH]c1C(=O)O</smiles>

$12(20 \%)$

Scheme 8

thus lowering the yield of the desired rearrangement product and rendering its purification troublesome. More importantly, the yields of the products are not uniformly reproducible. Nevertheless, this reaction has been successfully applied in the synthesis of the targeted pentacarboxylic porphyrin $4^{16}$.

\section{Experimental}

Melting points were determined in Kofler block and Toshniwal apparatus. Hemin (Sigma) and thallium(III) nitrate trihydrate (Aldrich) were used. Silica gel G (Merck) was used for thin layer chromatography (both analytical and preparative) and neutral alumina, grade III (Merck) and grade IV (B.D.H.) were used for column chromatography. Anhydrous magnesium sulfate was used for drying solutions. Mass spectra refer to EI-MS, and ${ }^{1} \mathrm{H}$ NMR spectra $(90 \mathrm{MHz}$; $\mathrm{CDCl}_{3}$ ) were recorded in a Varian EM-390 spectrometer. Petrol refers to petroleum ether, b.p. $60-80^{\circ}$. All new compounds showed correct results for elemental analyses, carried out in the University College, Cardiff, U.K.

Monoacetyl-DP-LX-DME (9) and diacetyl-DP- $L X-D M E$ (10): Following literature procedure ${ }^{7}$, deuteroporphyrin IX dimethyl ester (8) was first isolated from hemin. Preparation of its copper chelate, acetylation of the latter by acetic anhydride in benzene solution in presence of catalytic amount of stannic chloride, and chromatographic separation over neutral alumina furnished the two acetyl derivatives in $\mathrm{CH}_{2} \mathrm{Cl}_{2}$ eluates : 10, red needles, m.p. $240-242^{\circ}\left(\mathrm{CHCl}_{3}\right.$ $\mathrm{MeOH})\left(\right.$ lit. $\left.^{7} 244^{\circ}\right) ; \mathrm{M}^{+} 622 ; \lambda_{\max }\left(\mathrm{CH}_{2} \mathrm{Cl}_{2}\right) 420(\log \varepsilon 5.15)$ (Soret band), 515 (4.13), 550 (3.87), 585 (3.78), $640 \mathrm{~nm}$ (3.54); 9 (mixture of the 2-/4-monoacetyl derivatives), red amorphous solid; $\mathrm{M}^{+} 580 ; \lambda_{\max }\left(\mathrm{CH}_{2} \mathrm{Cl}_{2}\right) 410$ (5.30), 505 
(4.07), 545 (4.11), 575 (3.89), $630 \mathrm{~nm}(3.30)$.

Reaction of 9 with thallic nitrate: To a solution of 9 (29 $\mathrm{mg} ; 0.05 \mathrm{mM}$ ) in a mixture of $\mathrm{CH}_{2} \mathrm{Cl}_{2}(5 \mathrm{ml})$ and $\mathrm{MeOH}$ $(10 \mathrm{ml})$ was added a solution of thallic nitrate trihydrate $(50$ $\mathrm{mg} ; 0.11 \mathrm{mM})$ in $\mathrm{MeOH}(5 \mathrm{ml})$, followed by a drop of conc. nitric acid. The solution was stirred overnight at room temperature, when the reaction was found (TLC) to be complete. The white precipitate of thallous nitrate was filtered off, the filtrate diluted with $\mathrm{CH}_{2} \mathrm{Cl}_{2}(20 \mathrm{ml})$, washed first with dilute ammonia and then with water, dried and the solvent distilled off. The resulting residue was demetallated $\left(\mathrm{CH}_{2} \mathrm{Cl}_{2}-\mathrm{MeOH} / \mathrm{SO}_{2}(\mathrm{~g}) / \text { conc. } \mathrm{HCl}\right)^{6}$, reesterified $(5 \%$ $\mathrm{H}_{2} \mathrm{SO}_{4} / \mathrm{MeOH}$ ) and chromatographed over alumina (grade III) to furnish in $\mathrm{C}_{6} \mathrm{H}_{6}-\mathrm{CH}_{2} \mathrm{Cl}_{2}(1: 1)$ eluate a product which was found to be slightly impure. It was finally purified by preparative TLC (double run) over silica gel in petrol-EtOAc $(3: 2)$ to furnish 11 as a red amorphous solid $(5 \mathrm{mg}, 16 \%)$, $\mathrm{C}_{35} \mathrm{H}_{38} \mathrm{~N}_{4} \mathrm{O}_{6} ; \mathrm{m} / z 611\left(\mathrm{M}^{+}\right) ; \lambda_{\max }\left(\mathrm{CH}_{2} \mathrm{Cl}_{2}\right)$ 397.5, 498, $531,571,624 \mathrm{~nm} ;{ }^{1} \mathrm{H}$ NMR $\delta 3.27(4 \mathrm{H}$, br t, $2 \times$ $\left.\mathrm{CH}_{2} \mathrm{CH}_{2} \mathrm{CO}_{2} \mathrm{Me}\right), 3.63(15 \mathrm{H}, \mathrm{s}, 4 \times$ ring $\mathrm{Me}$ and $1 \times$ $\left.\mathrm{CO}_{2} \mathrm{Me}\right), 3.75\left(6 \mathrm{H}, \mathrm{s}, 2 \times \mathrm{CO}_{2} \mathrm{Me}\right), 4.43(4 \mathrm{H}$, br t, $2 \times$ $\left.\mathrm{ArCH}_{2} \mathrm{CH}_{2}\right), 5.06\left(2 \mathrm{H}, \mathrm{s}, \mathrm{ArCH}_{2} \mathrm{CO}_{2} \mathrm{Me}\right), 9.13(1 \mathrm{H}, \mathrm{s}$, 2-/4-H), $10.14(4 \mathrm{H}$, diffused signal, $4 \times$ meso- $\mathrm{H})$.

Reaction of 10 with thallic nitrate: A solution of the diacetylporphyrin 10 ( $31 \mathrm{mg} ; 0.05 \mathrm{mM}$ ) in $\mathrm{CH}_{2} \mathrm{Cl}_{2}(5 \mathrm{ml})$ $\mathrm{MeOH}(10 \mathrm{ml})$ was treated with a solution of thallic nitrate trihydrate $(70 \mathrm{mg} ;>0.15 \mathrm{~m})$ in $\mathrm{MeOH}(10 \mathrm{ml})$ at $35-40^{\circ}$ for nearly $5 \mathrm{~h}$. A similar work-up as before and initial purification by $\mathrm{CC}$ over grade IV alumina furnished the product in $\mathrm{C}_{6} \mathrm{H}_{6}-\mathrm{CH}_{2} \mathrm{Cl}_{2}(4: 1)$ eluate. It was purified by preparative TLC (double run) in $\mathrm{C}_{6} \mathrm{H}_{6}$-EtOAc $(3: 1)$ to furnish 12 as red needles $\left(4.5 \mathrm{mg}, 13 \%\right.$ ), m.p. 219-222 ${ }^{\circ}$ (petrol$\left.\mathrm{CH}_{2} \mathrm{Cl}_{2}\right), \mathrm{C}_{38} \mathrm{H}_{42} \mathrm{~N}_{4} \mathrm{O}_{8}, \mathrm{~m} / z 682\left(\mathrm{M}^{+}\right) ; \lambda_{\max }\left(\mathrm{CH}_{2} \mathrm{Cl}_{2}\right) 401$, $500,533.5,572,625 \mathrm{~nm}$; ${ }^{1} \mathrm{H}$ NMR $\delta 3.25(4 \mathrm{H}$, br s, $2 \times$ $\left.\mathrm{CH}_{2} \mathrm{CH}_{2} \mathrm{CO}_{2} \mathrm{Me}\right), 3.62(21 \mathrm{H}, \mathrm{s})$ and $3.74(3 \mathrm{H}, \mathrm{s}), 4 \times$ ring Me and $\left.4 \times \mathrm{CO}_{2} \mathrm{Me}\right), 4.40\left(4 \mathrm{H}, \mathrm{m}, 2 \times \mathrm{ArCH}_{2} \mathrm{CH}_{2}\right), 5.04$ $\left(4 \mathrm{H}, \mathrm{s}, 2 \times \mathrm{ArCH}_{2} \mathrm{CO}_{2} \mathrm{Me}\right), 10.10(4 \mathrm{H}$, br s, $4 \times$ meso $-\mathrm{H})$.

Synthesis of 12 : The 5,5'-diformylpyrromethane 14 was prepared ${ }^{14}$ from the pyrrole 13 by sequential acid-catalysed dimerisation, hydrogenolysis and formylation (DMF$\mathrm{POCl}_{3}$ ). The pyrromethane-5,5'-dicarboxylic acid $15^{15}$ was derived from the corresponding dibenzyl ester $(25 \mathrm{mg} ; 0.04$ $\mathrm{m} M)$ by hydrogenolysis $\left(\mathrm{H}_{2} / 10 \% \mathrm{Pd}-\mathrm{C}, 10 \mathrm{mg} / \mathrm{Et}_{3} \mathrm{~N}\right.$, one drop). To a solution of 15 , thus obtained, in $\mathrm{CH}_{2} \mathrm{Cl}_{2}$ (25 $\mathrm{ml}$ ) was added $\mathrm{MeOH}(3.5 \mathrm{ml})$, followed by $14(16 \mathrm{mg}$; $0.04 \mathrm{~m} M$ ) and $p$-toluene sulfonic acid $(80 \mathrm{mg})$. The solution was kept overnight at room temp. in the dark. A saturated methanolic solution $(3.5 \mathrm{ml})$ of zinc acetate dihydrate was then added to it, and the reaction mixture kept in the dark for 2 days. Usual work-up, viz. methanolysis (5\% $\mathrm{H}_{2} \mathrm{SO}_{4} / \mathrm{MeOH}$ ) and subsequent demetallation furnished the crude product. It was purified by $\mathrm{CC}$ over grade IV alumina, when $\mathrm{C}_{6} \mathrm{H}_{6}-\mathrm{CHCl}_{3}(3: 1)$ eluate furnished pure 12 , m.p. $220-222.5^{\circ}$ (petrol $-\mathrm{CH}_{2} \mathrm{Cl}_{2}$ ) in $20 \%$ yield $(5.5 \mathrm{mg}$ ); $\lambda_{\text {max }}\left(\mathrm{CH}_{2} \mathrm{Cl}_{2}\right) 402,500,534,572,625 \mathrm{~nm}$. Its identity with the rearranged product $\mathbf{1 2}$ was confirmed by direct comparisons (m.m.p., co-TLC).

\section{Acknowledgement}

The author is indebted to Professor A. H. Jackson (since deceased), in whose laboratory in the Department of Chemistry, (the then) University College, Cardiff, U.K., a part of this work was carried out years ago. Thanks are also due to my students, Ramkrishna Basak and Nandita Ghosh, for their help in preparing this manuscript.

\section{References}

1. J. Fajer, Chem. Ind. 1991, 869.

2. A. H. Jackson, H. A. Sancovich, A. M. Ferramola, N. Evans, D E. Games, S. A. Matlin, G. H. Elder and S. G. Smith,Phil. Trans. R. Soc. London B, 1976, 273, 191

3. A. McKillop, B. P. Swan and E. C. Taylor, J. Am. Chem. Soc., 1973, 95, 3340 .

4. R. J. Abraham, G. H.Barnett, E. S. Bretschneider and K. M. Smith, Tetrahedron, 1973, 29, 553

5. G. H. Barnett, M. F. Hudson, S. W. McCombie and K. M. Smith, J. Chem. Soc., Perkin Trans. 1, 1973, 691.

6. R. J. Abraham, G. H. Barnett and K. M. Smith, J. Chem. Soc., Perkin Trans. 1, 1973, 2142.

7. H. Brockmann, Jr., K.-M. Bliesener and H. H. Inhoffen, Justus Liebigs Ann. Chem., 1968, 718, 148

8. O. Schumm, Z. Physiol. Chem., 1928, 176, 122; 1928, 178, 1; 1929, 181, 141.

9. M. Grinstein, J. Biol. Chem., 1947, 167, 515.

10. R. Bonnett, I. H. Campion-Smith and A. J. Page, J. Chem. Soc., Perkin Trans. I, 1977, 68

11. A. Valasinas and B. Frydman, J. Org. Chem., 1976, 41, 2991.

12. G. P. Arsenault, E. Bullock and S. F. MacDonald, J. Am. Chem. Soc., 1960, 82, 4384 .

13. E. J. Tarlton, S. F. MacDonald and E. Baltazzi, J. Am. Chem. Soc., 1960, 82, 4389.

14. R. Chong, P. S. Clezy, A. J. Liepa and A. W. Nichol, Aust. J. Chem. 1969, 22, 229.

15. H. M. G. Al-Hazimi, Ph.D. Dissertation, University College, Cardiff, U.K., 1976.

16. M. Chakrabarty and A. H. Jackson, unpublished work. 